\title{
Colaboração científica e produtividade na pós-graduação em Sociologia e Ciências Sociais no Brasil
}

\author{
Scientific collaboration and productivity in Sociology and Social Sciences \\ graduate programs in Brazil
}

\section{Colaboración científica y productividad en los programas de postgrado en Sociología y Ciencias Sociales en Brasil}

http://dx.doi.org/10.221713/2358-2332.2016.v14.1291 ${ }^{1}$

Velcimiro Inácio Maia, doutor em Sociologia pela Universidade Federal de Minas Gerais (UFMG), membro do Grupo Interdisciplinar de Pesquisa em Análise de Redes Sociais (Giars), professor da Universidade Federal de São João Del-Rei (UFSJ), São João Del-Rei, MG, Brasil. E-mail:maia@ufsj.edu.br.

\section{Resumo}

Este estudo descreve a evolução da coesão social e da produtividade científica na área da Sociologia e das Ciências Sociais no Brasil por meio das redes de coautoria científica do corpo docente atuante na pós-graduação durante dois triênios. A pesquisa do tipo descritiva e explicativa utiliza como fonte de dados os currículos disponíveis na Plataforma Lattes do CNPq e os Cadernos de Indicadores da Capes. As relações de coautoria foram identificadas com o uso de uma ferramenta de mineração de dados e as redes foram analisadas com o auxílio de softwares de análise de redes sociais. Conclui-se que a área aumentou em tamanho, coesão social e produtividade e que os programas de pós-graduação com maior diversidade de laços se mostraram mais produtivos. Os resultados contribuem para a compreensão das interações interinstitucionais no campo, fornecendo subsídios para os atores envolvidos.

Palavras-chave: Análise de Redes Sociais. Colaboração Científica. Produtividade Científica.

\begin{abstract}
This article describes the evolution of social cohesion and scientific productivity in the field of Sociology and Social Sciences in Brazil through the networks of scientific co-authoring of professors working in graduate school for two three-year periods. The descriptive and explanatory study used résumés available in the Plataforma Lattes of $\mathrm{CNPq}$ and the Cadernos de Indicadores Capes as data sources. The co-authoring relationships were identified with the
\end{abstract}

\footnotetext{
${ }^{1}$ Como citar: ABNT NBR 6023:2002 e incluir o DOI.
} 
use of a data mining tool and the networks were analyzed with the aid of social networks analysis software. It can be concluded that the field has increased in size, social cohesion, and productivity and that graduate programs with a greater diversity of ties were more productive. The results contribute to the understanding of the inter-institutional interactions in the field, providing subsidies for the actors involved.

Keywords: Social Networks Analysis. Scientific Collaboration. Scientific Productivity.

\section{Resumen}

Este estudio describe la evolución de la cohesión social y la productividad científica en el área de Sociología y de Ciencias Sociales en Brasil a través de redes de coautoría científica de profesores actuantes en cursos de maestría y doctorado durante dos trienios. La investigación de tipo descriptiva y explicativa usa como fuente de datos los currículum vitae disponibles en la Plataforma Lattes del CNPq y las Listas de indicadores Capes. Las relaciones establecidas a lo largo del trabajo se identificaron con el auxilio de una herramienta de minería de datos, y las redes analizadas con el apoyo de softwares de análisis de redes sociales. Concluimos que el área aumentó en tamaño, cohesión social y productividad y que los programas de postgrado con una mayor diversidad de lazos se mostraron más productivos. Los resultados contribuyen a la comprensión de las interacciones interinstitucionales en el campo, ofreciendo subsidios a los actores involucrados.

Palabras clave: Análisis de Redes Sociales. Colaboración Científica. Productividad Científica.

\section{INTRODUÇÃO}

Neste trabalho, analisa-se a colaboração científica de forma restrita às coautorias em artigos, livros e capítulos de livros. Isto permite descrever as redes de coautoria formadas entre os pesquisadores atuantes nos Programas de Pós-Graduação em Sociologia e Ciências Sociais (PPGS) avaliados pela Coordenação de Aperfeiçoamento de Pessoal de Nível Superior (Capes) nos triênios compreendidos entre os anos de 2007 a 2009 e 2010 a 2012. Pela análise das redes, busca-se descrever como a área ${ }^{2}$ evoluiu de um triênio para outro em termos de coesão social e produtividade.

O artigo trabalha com três níveis de análise: as relações de coautoria entre os pesquisadores; as suas filiações institucionais; e a visão da área como um todo. Portanto, parte-

\footnotetext{
${ }^{2}$ Segundo os relatórios de avaliações trienais da Capes de 2010 e 2013, a área possui a singularidade de englobar programas de Sociologia e Ciências Sociais, sendo que os programas de Ciências Sociais abrangem três disciplinas: Sociologia, Antropologia e Ciência Política. A área contempla os cursos de Sociologia; Sociologia e Antropologia; Sociologia e Política; Sociologia Política; Ciências Sociais; Ciências Sociais em Desenvolvimento, Agricultura e Sociedade; Ciências Sociais: Cultura, Desigualdades e Desenvolvimento; Ciências Sociais: Defesa Social e Mediação de Conflitos; Planejamento e Políticas Públicas; Políticas Públicas e Sociedade. (COORDENAÇÃO DE APERFEIÇOAMENTO DE PESSOAL DE NÍVEL SUPERIOR, 2010, 2013)
} 
se da discussão das posições dos pesquisadores na rede, para a discussão das posições dos PPGS na área. Por outro lado, mede-se a produtividade de cada PPGS e da área como um todo, permitindo correlacionar as métricas de redes com a produtividade.

\section{PERCURSO METODOLÓGICO}

Pautou-se este estudo na coleta de dados secundários oriundos dos próprios PPGS, disponibilizados publicamente pela Capes. As fontes de dados foram o site da Capes e a base de currículos da Plataforma Lattes. Primeiramente, identificaram-se todos os PPGS avaliados pela Capes. O passo seguinte consistiu na listagem do corpo docente atuante. De posse da lista de docentes, foi possível localizar os códigos utilizados pelo CNPq como identificadores (ID) dos currículos Lattes. Assim, três listagens com nomes e ID foram montadas: uma para cada um dos dois triênios e uma considerando o período total de 2007 a 2012. Este foi o ponto de partida para a coleta utilizando o software de mineração de dados Scriptlattes (MENACHALCO; CESAR JUNIOR, 2009).

As produções bibliográficas disponíveis nos currículos Lattes com títulos iguais ou similares, dentro do mesmo tipo e ano de publicação, foram consideradas como colaborações entre autores. O script foi ajustado para considerar somente artigos completos publicados em periódicos, livros publicados, organizados ou editados e capítulos de livros. As redes de coautoria geradas são endógenas, isto é, consideram somente as relações entre os pesquisadores listados. Adotou-se a metodologia de análise de redes sociais (ARS) com auxílio dos softwares Pajek 3.13, Ucinet 6.491, Netdraw 2.135 e Gephi 0.8.2.

Os professores que participavam simultaneamente de mais de um programa foram atribuídos ao PPGS no qual se mantiveram por mais tempo como docentes permanentes no triênio. Também foram levantadas as publicações bibliográficas dos PPGS durante os dois triênios. A coleta foi realizada em 10 de abril de 2015, e quaisquer dados inseridos nos currículos Lattes após esta data não constaram nas redes.

\section{REDES DE COATORIA}

No primeiro triênio, 42 PPGS foram compostos por 883 docentes. Destes, 256 possuíam pelo menos um laço de coautoria, ou seja, apenas $28,99 \%$ possuíam pelo menos um artigo, livro ou capítulo de livro em coautoria com outros pesquisadores deste universo. A Figura 1 mostra os integrantes da rede (os atores sem laços de coautoria não aparecem nessa visualização). 


\section{Figura 1 - Docentes com coautoria no $1^{\circ}$ triênio}

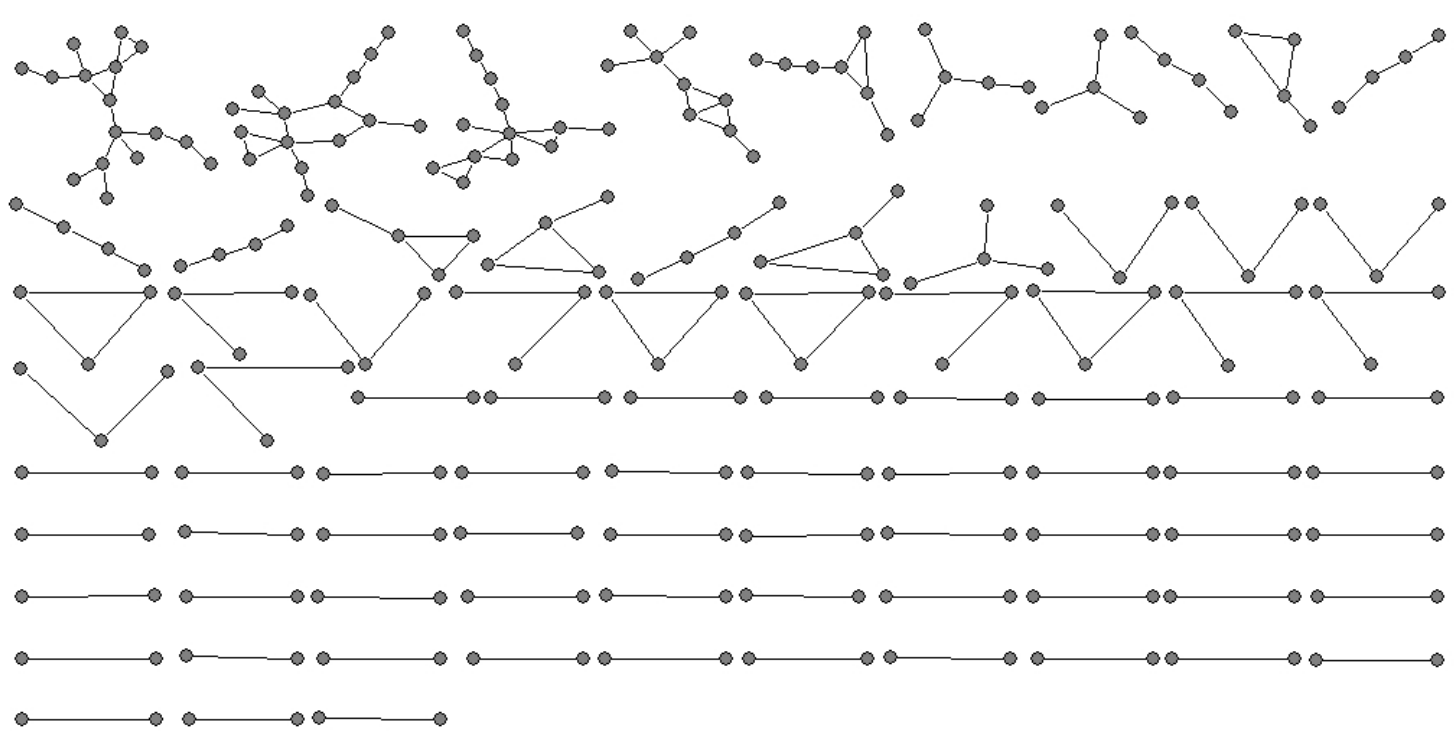

Fonte: Elaborado pelo autor a partir de dados da Plataforma Lattes.

A rede de coautoria do primeiro triênio se mostrou muito fragmentada. Foram encontrados 83 componentes $^{3}$. Os analistas de redes sociais geralmente optam por concentrar seus estudos nos aspectos do componente gigante, ou seja, o maior subgrafo conexo, que quase sempre engloba a maior parte dos atores. No caso desse triênio, o maior componente continha apenas 16 atores enquanto $71,01 \%$ dos professores não possuíam laços de coautoria.

Já o segundo triênio, que englobou 52 PPGS, continha 1.060 docentes. Destes, 365 apresentavam-se conectados. Portanto, 34,43\% dos professores possuíam laços de coautoria (Figura 2). Percebe-se a evolução em termos de coesão social entre os dois triênios, dado o aumento percentual de pesquisadores ligados (de $28,99 \%$ para $34,43 \%$ ).

\footnotetext{
${ }^{3}$ Componente em um grafo é um conjunto de nós, em que cada nodo tem um caminho para todos os outros nós do conjunto.
} 


\section{Figura 2 - Docentes com coautoria no $2^{\circ}$ triênio}

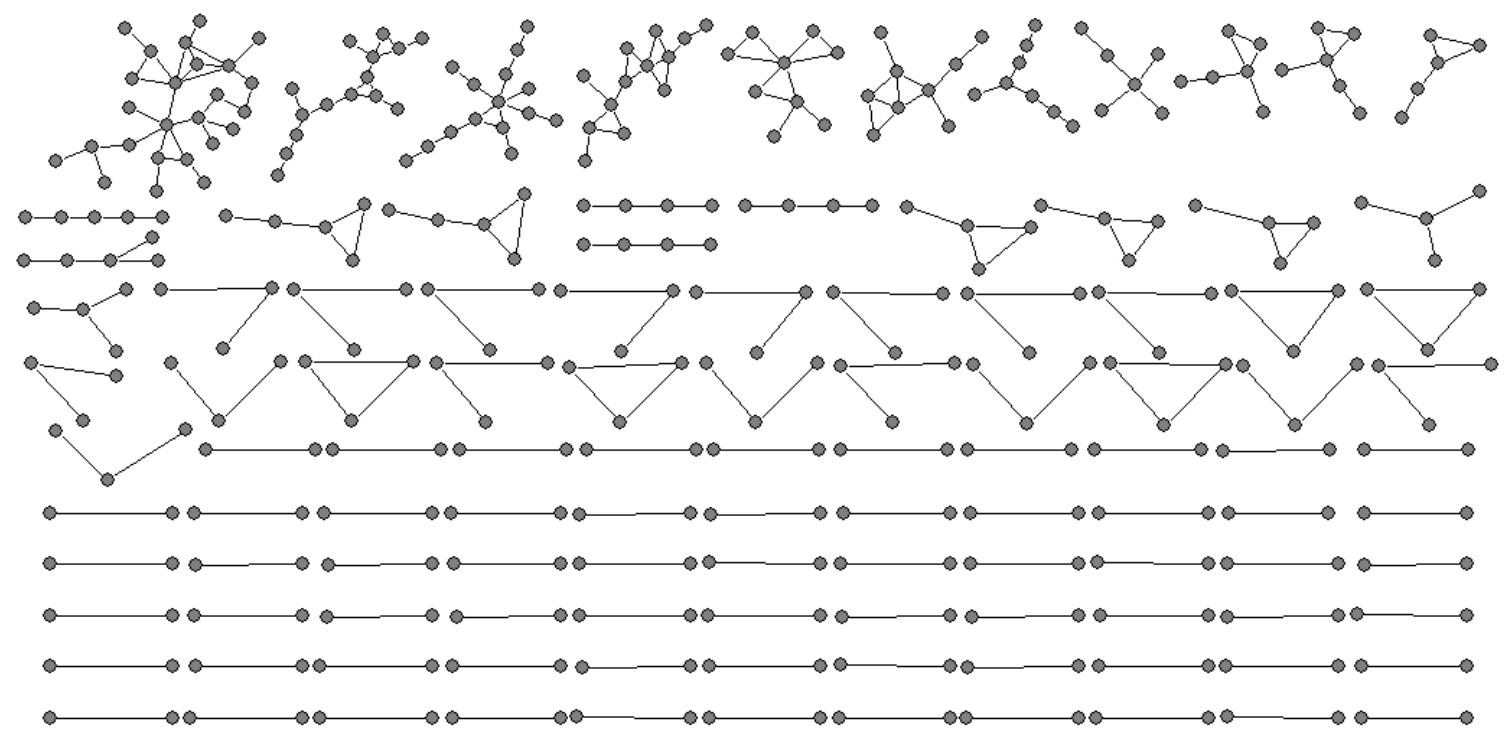

Fonte: Elaborado pelo autor a partir de dados da Plataforma Lattes.

O segundo triênio apresentou 110 componentes, e o maior continha apenas 25 atores. Vale ressaltar que $65,57 \%$ dos docentes não possuíam laços. A estratégia de coautoria na produção não é uma característica marcante na área de Sociologia, muitas publicações são individuais, principalmente as de linha mais literária e teórica. A rede de coautoria expressa o grau de colaboração científica de um campo, visto que ela reflete a produção e a divulgação das pesquisas realizadas por seus integrantes. As redes dos dois triênios considerados mostraram um nível de coesão baixo para o campo da Sociologia se comparado a outros campos científícos.

\section{REDES REDUZIDAS}

Nas redes de coautoria, o que liga os atores não são as instituições, mas sim as publicações com dois ou mais autores. No entanto, a transformação das redes segundo as afiliações institucionais dos atores constitui uma estratégia metodológica necessária para operacionalizar a análise da área como um todo. Entendemos que se um ator pertence a determinado PPGS, deve ter algum contato com os demais atores daquele programa, presumindo assim a existência de relação social entre eles. Portanto, podemos reduzir as redes, considerando somente as instituições. Para isso, os vértices equivalentes aos atores pertencentes a uma mesma instituição foram transformados em um só vértice: o do PPGS ao qual estão filiados.

É oportuno destacar que o programa da Universidade Federal de Alagoas (Ufal) não aparece na rede de coautoria reduzida do primeiro triênio, pois seus pesquisadores não apresentaram coautoria nesse período. No segundo triênio, todos os PPGS apresentaram pesquisadores com alguma coautoria. Por isso, os 52 programas são apontados na rede em nível interinstitucional (Figuras 3 e 4). 
Maia / Colaboração científica e produtividade na pós-graduação em Sociologia e Ciências Sociais no Brasil

\section{Figura 3 - Rede reduzida do $1^{\circ}$ triênio}

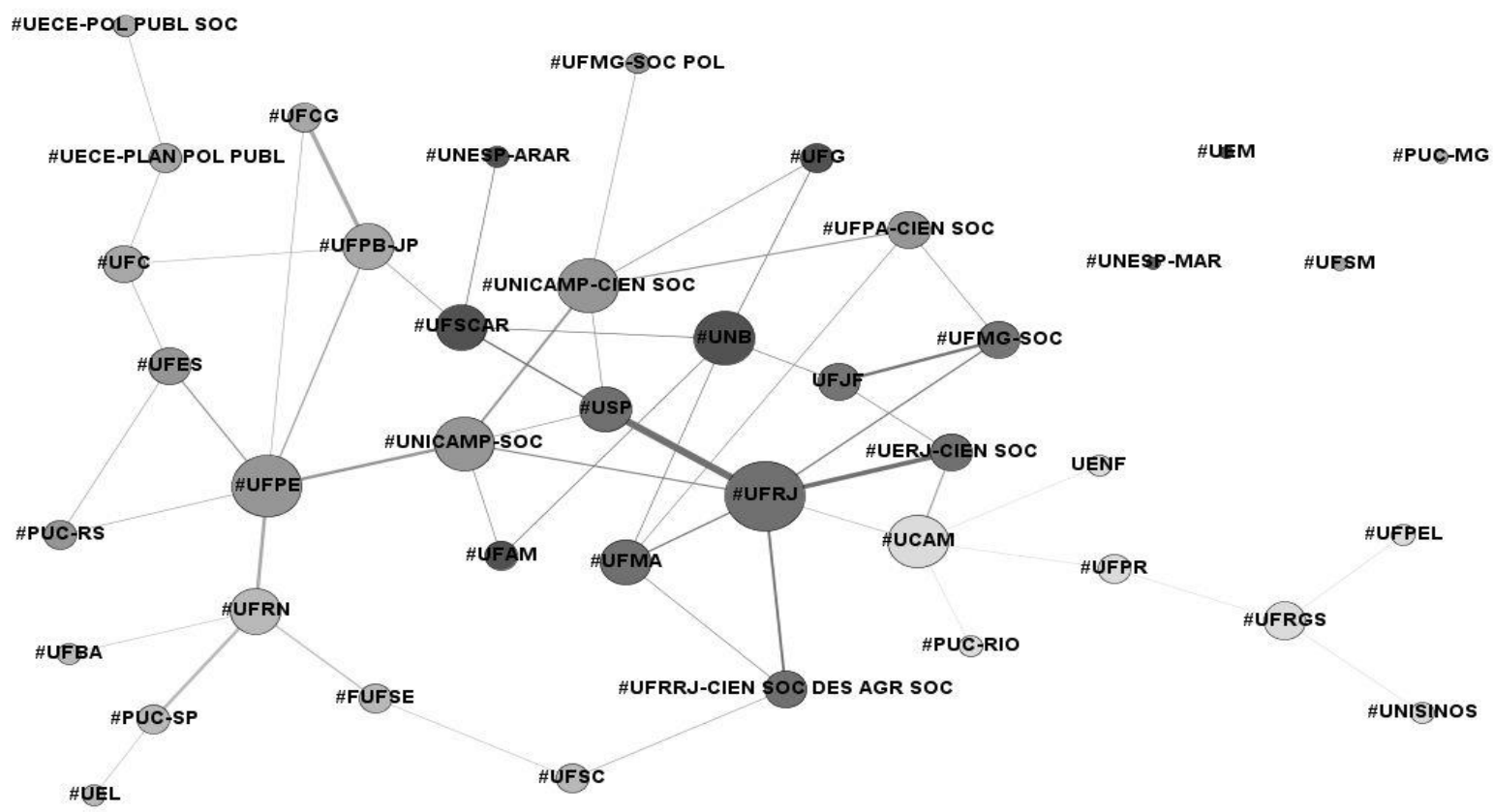

Fonte: Elaborado pelo autor a partir de dados da Plataforma Lattes.

Nota: O tamanho dos vértices indica a centralidade de grau, as tonalidades indicam as comunidades e \# indica PPGS com mais de um pesquisador.

\section{Figura 4 - Rede reduzida do $2^{\circ}$ triênio}

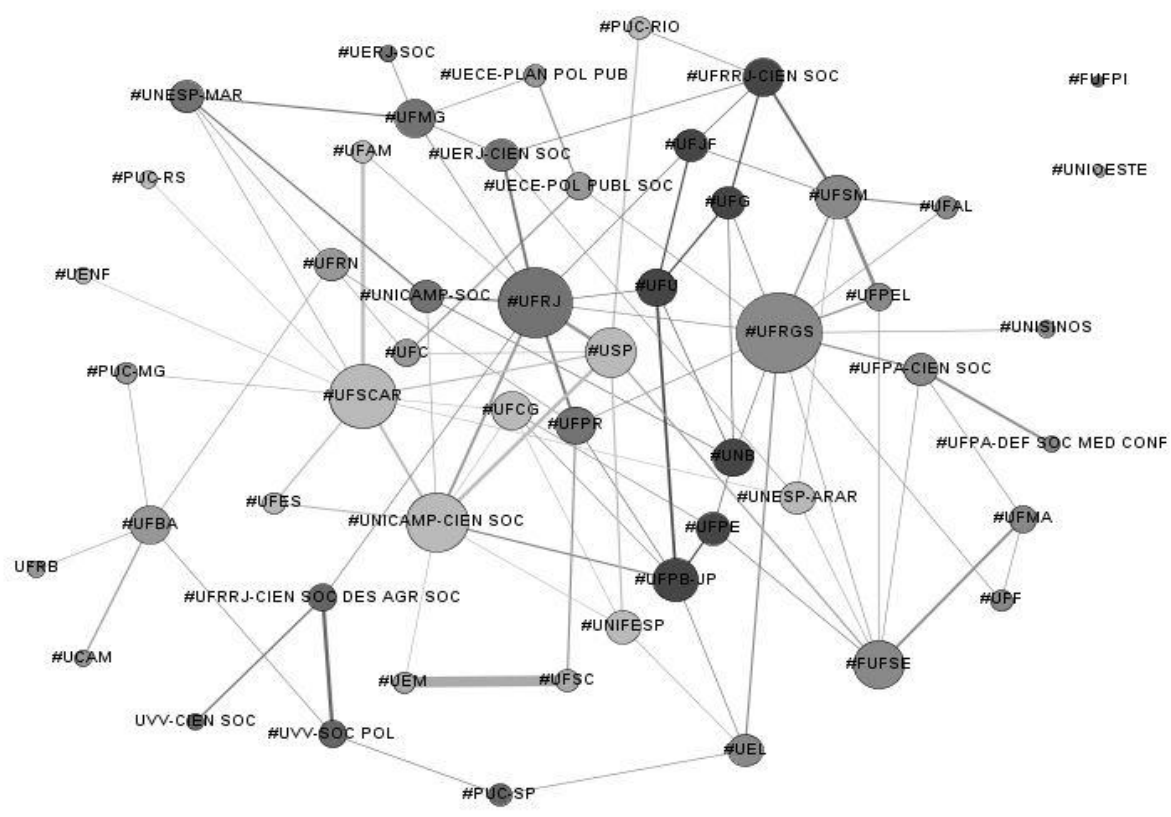

Fonte: Elaborado pelo autor a partir de dados da Plataforma Lattes.

Nota: O tamanho dos vértices indica a centralidade de grau, as tonalidades indicam as comunidades e \# indica PPGS com mais de um pesquisador. 
Maia / Colaboração científica e produtividade na pós-graduação em Sociologia e Ciências Sociais no Brasil

As redes foram segmentadas pelas comunidades formadas segundo a densidade de relações ${ }^{4}$. A rede do primeiro triênio foi estratificada em sete comunidades, sendo que quatro PPGS estavam desconectados, pois tinham somente coautorias internas. No segundo triênio, também foram identificadas sete comunidades, sendo dois PPGS desconectados (conforme Quadro 1).

\section{Quadro 1 - Comunidades de coautoria}

\begin{tabular}{|l|l|}
\hline \multicolumn{1}{|c|}{$\mathbf{1}^{\mathbf{0}}$ triênio } & \multicolumn{1}{c|}{$\mathbf{2}^{\mathbf{0}}$ triênio } \\
\hline $\begin{array}{l}\text { Unicamp-Soc; UFPe; Unicamp-Cien Soc; UFMG- } \\
\text { Soc Pol; Ufpa-Cien Soc; Ufes; PUC-RS }\end{array}$ & $\begin{array}{l}\text { PUC-MG; UFRB; Uece-Plan Pol Pub; Uece-Pol } \\
\text { Publ Soc; UFRN; UFC; Ufba; Ucam }\end{array}$ \\
\hline $\begin{array}{l}\text { UFRJ; USP; Uerj-Cien Soc; Ufma; UFRRJ-Cien Soc } \\
\text { Des Agr Soc }\end{array}$ & $\begin{array}{l}\text { UnB; UFU; UFPB-JP; UFJF; UFRRJ-Cien Soc; } \\
\text { UFG; UFPe }\end{array}$ \\
\hline $\begin{array}{l}\text { PUC-RIO; Unisinos; UFPR; UFRGS; Ufpel; Uenf; } \\
\text { Ucam }\end{array}$ & UFSC; UEM \\
\hline UFJF; UFMG-Soc & $\begin{array}{l}\text { Uerj-Soc; UFMG; Unesp-MAR; Unicamp-Soc; Uerj- } \\
\text { Cien Soc; UFPR; UFRJ }\end{array}$ \\
\hline UEL; PUC-SP; UFSC; Ufba; UFRN; Fufse & $\begin{array}{l}\text { PUC-RS; UFCG; Ufam; Ufes; PUC-RIO; Unesp- } \\
\text { ARAR; Unicamp-Cien Soc; Unifesp USP; Uenf; } \\
\text { UFSCar }\end{array}$ \\
\hline UFG; UnB; Ufam; Unesp-ARAR; UFSCar & $\begin{array}{l}\text { Ufpa-Def Soc Med Conf; Unisinos; UFF; Ufal; } \\
\text { UFSM; UFRGS; Ufpel; UEL; Fufse; Ufma; Ufpa- } \\
\text { Cien Soc }\end{array}$ \\
\hline Uece-Pol Publ Soc; Uece-Plan Pol Publ; UFCG; & $\begin{array}{l}\text { UFRRJ-Cien Soc Des Agr Soc; UVV-Cien Soc; } \\
\text { UVV-Soc Pol; PUC-SP }\end{array}$ \\
\hline
\end{tabular}

Fonte: Elaborado pelo autor a partir de dados da Plataforma Lattes.

\section{EXTERNALIDADE DAS RELAÇÕES}

Verificamos se há preferência dos atores por tecer relações externas. Para tanto, avaliamos a tendência de laços por meio do algoritmo E-I Index, que compara os números de laços dentro e fora das partições e possui amplitude que varia de -1 a 1. O E-I Index é calculado pelo número de laços externos menos o número de laços internos, dividido pelo número total de laços observados. Valores mais próximos de 1 indicam maior tendência de relacionamentos externos, enquanto valores mais próximos de -1 revelam a tendência de os atores se relacionarem internamente.

A Tabela 1 mostra o total de coautorias nos triênios. Para esta análise consideramos o número de coautorias entre cada par de atores conectados.

\footnotetext{
${ }^{4} \mathrm{O}$ algoritmo de comunidades no Gephi é um método heurístico baseado na otimização de modularidade e consiste em decompor as redes em subunidades de nós altamente interligados (BLONDEL et al., 2008; LAMBIOTTE; DELVENNE; BARAHONA, 2009).
} 
Maia / Colaboração científica e produtividade na pós-graduação em Sociologia e Ciências Sociais no Brasil

Tabela 1 - E-I Index por triênios

\begin{tabular}{c|r|r|r|r}
\hline Triênios & $\begin{array}{c}\text { Coautorias } \\
\text { externas (E) }\end{array}$ & $\begin{array}{r}\text { Coautorias } \\
\text { internas (I) }\end{array}$ & $\begin{array}{r}\text { Total de } \\
\text { coautorias }\end{array}$ & E-I Index \\
\hline $\mathbf{1}^{\mathbf{0}}$ & 188 & 206 & 394 & $-0,046$ \\
$\mathbf{2}^{\mathbf{0}}$ & 326 & 225 & 551 & 0,183 \\
\hline
\end{tabular}

Fonte: Elaborado pelo autor a partir de dados da Plataforma Lattes.

A homogeneidade institucional foi pequena no primeiro triênio, passando para um cenário de heterogeneidade no segundo. $\mathrm{O}$ total de coautorias aumentou 39,85\% de um triênio para outro e o aumento foi maior nas coautorias externas aos programas, visto pela elevação do E-I Index, que passou de $-0,046$ para 0,183 . Ou seja, de maneira geral, no segundo triênio, os pesquisadores publicaram mais em parceria com atores de outras instituições do que dentro de suas próprias.

Dos 40 PPGS atuantes nos dois triênios, 25 aumentaram o grau de externalidade em suas coautorias, enquanto somente 15 diminuíram o grau de externalidade. Dos 12 PPGS novos, que começaram suas atividades no segundo triênio, oito tiveram mais coautorias externas. Podese dizer que o aumento da externalidade nas coautorias serve como indicador de elevação da coesão social, visto que quanto mais relações externas, mais entrelaçada será a rede. Conforme a ótica do fluxo de informações e conhecimento, podemos conjecturar que a maior externalidade favorece a geração de novas ideias e aumenta a sinergia no campo científíco.

\section{COESÃO SOCIAL}

Se considerarmos apenas a existência ou não de relações de coautoria entre os atores dos diversos programas, teremos um foco na análise de diversidade de relações. Por outro lado, se considerarmos as quantidades de coautorias, teremos um foco na análise de força, de intensidade das relações. Para a análise de coesão optamos por utilizar a rede binária, pois a intenção foi analisar a diversidade de relações entre os programas, e não sua intensidade. Para isso, os programas que não possuíam coautorias externas foram excluídos.

Como mostra a Tabela 2, a média de laços por programa, o grau de centralidade da rede, a densidade e o coeficiente de agrupamento geral aumentaram de um triênio para outro, mostrando a evolução da coesão social do campo da Sociologia. A distância entre os programas diminuiu, visto que o diâmetro da rede e a distância geodésica média (os graus de separação) ficaram menores no segundo triênio. Mesmo com o aumento da quantidade média de laços, ou seja, da diversidade de contatos interinstitucionais, o coeficiente de agrupamento não sofreu grande elevação. Isto sugere que não houve forte tendência à formação de subgrupos.

Cada nó que se insere em uma rede faz com que a densidade diminua sobremaneira, a não ser que a quantidade de laços aumente muito. Por conseguinte, o aumento na quantidade de programas e de laços de coautoria não trouxe aumento significativo da densidade da rede, mas o aumento da média de laços por programa fornece um indício de evolução positiva da coesão social. O diâmetro de uma rede equivale ao caminho mais longo entre os caminhos mais 
curtos entre dois nós. A diminuição do diâmetro e da distância média geodésica indica que os programas se tornaram mais próximos entre si, outro indício de melhoria quanto à coesão da área.

\section{Tabela 2 - Estatísticas descritivas da estrutura das redes}

\begin{tabular}{c|cc}
\hline Descrição & \multicolumn{2}{|c}{ Triênios } \\
\cline { 2 - 3 } & $\mathbf{1}^{\mathbf{0}}$ & $\mathbf{2}^{\mathbf{0}}$ \\
\hline Quantidade de programas conectados (vértices) & 37 & 50 \\
Laços de coautoria científica (arestas) & 104 & 194 \\
Média de laços por programa & 2,811 & 3,880 \\
Grau de centralidade total da rede (degree) & 0,123 & 0,193 \\
Densidade da rede & 0,156 & 0,158 \\
Diâmetro da rede & 10 & 6 \\
Distância média geodésica & 3,8 & 2,9 \\
Coeficiente de agrupamento geral & 0,155 & 0,167 \\
\hline
\end{tabular}

Fonte: Elaborado pelo autor a partir de dados da Plataforma Lattes.

Outra forma de observar a coesão é a contagem de cliques, ou subgrupos de completa mutualidade. Num clique, cada ator de um subgrupo possui relação com os demais do subgrupo, perfazendo uma densidade completa. A intuição popular que mais se assemelha ao conceito de clique é a de "panelinha", aqueles grupos em que todos conhecem a todos. Nas redes dos dois triênios analisados, não houve clique que englobasse mais de três PPGS. Na rede do primeiro triênio, existiam apenas seis cliques e, no segundo, passaram a existir 20. Mesmo não havendo aumento no tamanho dos cliques, o aumento do número destes corrobora a hipótese do aumento da coesão social da área.

\section{CENTRALIDADE E PODER}

Freeman $(1977,1979)$ desenvolveu três medidas a partir da noção de centralidade. Essas medidas tentam especificar e comparar a posição mais ou menos central dos vértices em um grafo. $\mathrm{O}$ autor se baseou em três intuições para mensurar a centralidade de um vértice: o grau de laços que o vértice tem com seus vizinhos (degree); sua proximidade em relação aos outros (closeness); e sua posição de intermediação na rede (betweenness).

\subsection{Centralidade de grau}

Mede a atividade relacional direta de um ator, ou seja, a quantidade de laços que um ator possui. A intuição é que o ator mais central na rede é aquele que concentra o maior número de conexões diretas com outros. A Tabela 3 mostra os PPGS mais conectados. No primeiro triênio, os programas apresentaram centralidade de grau variando de um a sete laços, no segundo, os programas apresentaram centralidade de grau variando de um a 13 laços. 
Maia / Colaboração científica e produtividade na pós-graduação em Sociologia e Ciências Sociais no Brasil

Tabela 3 - Programas com maior centralidade de grau

\begin{tabular}{cccc}
\hline \multicolumn{1}{c|}{$\mathbf{1}^{\mathbf{0}}$ Triênio } & \multicolumn{2}{c}{$\mathbf{2}^{\mathbf{0}}$ Triênio } \\
\hline Instituição & Degree centrality & Instituição & Degree centrality \\
\hline UFRJ & 7.000 & UFRGS & 13.000 \\
UFPe & 6.000 & UFRJ & 11.000 \\
Ucam & 5.000 & UFSCar & 10.000 \\
UnB & 5.000 & Unicamp-Cien Soc & 9.000 \\
Unicamp-Soc & 5.000 & Fufse & 7.000 \\
Ufma & 4.000 & USP & 7.000 \\
UFPB-JP & 4.000 & UFPB-JP & 6.000 \\
UFRN & 4.000 & UFSM & 6.000 \\
UFSCar & 4.000 & UFPR & 5.000 \\
Unicamp-Cien Soc & 4.000 & UFR J-Cien Soc & 5.000 \\
USP & 4.000 & Ufba & 5.000 \\
& & UFU & 5.000 \\
& & UFMG & 5.000 \\
& & UFCG & 5.000 \\
& & UnB & 5.000 \\
\hline
\end{tabular}

Fonte: Elaborado pelo autor a partir de dados da Plataforma Lattes.

\subsection{Centralidade de proximidade}

Procura medir a capacidade de autonomia ou de independência dos atores e é dada pelo inverso da distância geodésica total de um vértice a todos os outros da rede. Mede também a capacidade de atingir aos outros e não ser atingido por eles diretamente. A Tabela 4 mostra os programas com maior centralidade de proximidade.

Tabela 4 - Programas com maior centralidade de proximidade

\begin{tabular}{l|l|lc}
\hline \multicolumn{1}{l}{$\mathbf{1}^{\mathbf{0}}$ Triênio } & $\mathbf{2}^{\mathbf{0}}$ Triênio & \multicolumn{1}{c}{ Closeness } \\
\hline Instituição & nCloseness & Instituição & 49.495 \\
\hline Unicamp-Soc & 39.080 & UFRJ & 46.667 \\
UFRJ & 38.636 & UFRGS & 44.954 \\
USP & 36.170 & USP & 43.750 \\
UFPE & 35.789 & Unicamp-Cien Soc & 43.363 \\
UnB & 34.694 & UFPR & 41.176 \\
Ufma & 34.000 & UFSCar & 40.164 \\
UFSCar & 33.663 & Fufse & 38.889 \\
Uerj & 33.010 & Unicamp-Soc & 38.889 \\
Ucam & 31.776 & Unesp-Arar & 38.889 \\
Unicamp-Cien Soc & 31.193 & UFPB-JP & \\
\hline
\end{tabular}

Fonte: Elaborado pelo autor a partir de dados da Plataforma Lattes.

A proximidade (closeness) é medida tomando-se o inverso do afastamento (farness). Farness é a soma das distâncias geodésicas de um vértice para todos os outros vértices, closeness é o inverso do farness. O nCloseness (normalizado) é obtido pelo distanciamento 
dividido pelo distanciamento mínimo possível expresso como uma percentagem. (LEMIEUX; OUIMET, 2012).

\subsection{Centralidade de intermediação}

Descreve a capacidade que os atores têm de assegurar um papel de coordenação e controle. Essa centralidade vem da posição intermediária que um ator ocupa, de forma que muitos atores precisam passar por ele para alcançar os outros. Isto confere ao ator maior controle sobre a circulação de informações. Também mede a frequência com que um nó aparece nos caminhos mais curtos entre os outros nós da rede. Betweenness é, portanto, uma medida do número de vezes que um vértice ocorre nas distâncias geodésicas entre os demais vértices. $\mathrm{O}$ nBetweenness (normalizado) é o betweenness dividido pelo betweenness máximo possível expresso como uma percentagem. A Tabela 5 mostra os programas com maiores centralidades de intermediação.

Tabela 5 - Programas com maior centralidade de intermediação

\begin{tabular}{l|l|l|l}
\hline $\mathbf{1}^{\mathbf{0}}$ Triênio & nBetweenness & 2 & Triênio \\
\hline Instituição & 40.755 & \#UFRGS & nBetweenness \\
\hline \#UFRJ & 31.551 & \#UFRJ & 28.435 \\
\#Ucam & 28.399 & \#UFSCar & 25.314 \\
\#UFPE & 27.701 & \#USP & 17.641 \\
\#Unicamp-Soc & 16.878 & \#Unicamp-Cien Soc & 10.715 \\
\#UFRN & 16.578 & \#UFPR & 10.145 \\
\#UFPR & 14.765 & \#Ufba & 9.855 \\
\#UFSCar & 14.385 & \#Fufse & 9.824 \\
\#UFPB-JP & 12.353 & \#UFRN & 7.987 \\
\#UnB & 11.750 & \#UFMG & 7.968 \\
\#UFC &
\end{tabular}

Fonte: Elaborado pelo autor a partir de dados da Plataforma Lattes.

Nota-se que certos programas são recorrentes nas medidas de centralidade. De maneira geral, parece não haver mudança significativa na constituição das redes quanto aos programas que detêm a centralidade, ou seja, o poder, quanto à colaboração científica.

\section{BURACOS ESTRUTURAIS E BROKERS}

Além da importância dos laços fracos, Granovetter $(1973,1983)$ traz o conceito de pontes locais. Uma ponte local é a rota mais curta pela qual uma informação pode viajar de um subgrupo conectado entre si a outro subgrupo da rede total. Em redes complexas, raramente um vínculo específico proporciona um caminho único entre dois pontos, mas a função de ponte pode ser servida localmente. Para Granovetter (1973), somente um laço fraco poderia desempenhar essa função nas redes sociais complexas.

Burt (1992) complementa a noção de laços fracos e pontes locais de Granovetter (1973), 
trazendo o conceito de buracos estruturais e brokers. Buracos estruturais separam fontes de informações não redundantes, que são mais aditivas do que repetitivas. Há dois indicadores de redundância: coesão e equivalência. Contatos fortemente ligados uns aos outros são susceptíveis de terem informações semelhantes e, portanto, fornecerem mais informações redundantes. Contatos estruturalmente equivalentes têm as mesmas fontes de informação, por isso, também fornecem informações redundantes (BURT, 2001).

Broker é um ator que ocupa uma posição estrutural na extremidade de uma ponte entre dois setores de maior densidade dentro de uma rede. A posição de broker confere ao ator uma vantagem em termos de obtenção de informações mais ricas e privilegiadas, assim como de controle do fluxo de informações ou recursos entre os setores da rede (BURT, 1992). Um broker é um ator com habilidade de construir pontes interpessoais entre os buracos estruturais, fazendo a ligação entre duas redes, e pode lucrar obtendo as informações privilegiadas, além de possuir a capacidade de propagar novas ideias e comportamentos (GRANOVETTER, 2005).

$\mathrm{O}$ fator $\mathrm{C}$ (constraint index) ${ }^{5}$ mensura a ausência de buracos estruturais numa rede. A lógica apresentada por Burt (2001) é a de que quanto mais os alters de ego estão interconectados, sem a mediação de ego, maior será o constrangimento (constraint) da rede em ego. $\mathrm{O}$ fator $\mathrm{C}$ constitui uma medida para detectar os brokers de uma rede. Quanto menor o fator $\mathrm{C}$ de um ator, maior será seu papel como broker na rede (Tabela 6).

\section{Tabela 6 - Principais brokers}

\begin{tabular}{c|c|c|c}
\hline \multicolumn{1}{c|}{$\mathbf{1}^{\mathbf{0}}$ Triênio } & \multicolumn{2}{c}{$\mathbf{2}^{\mathbf{0}}$ Triênio } \\
\hline PPGS & constraint & PPGS & constraint \\
\hline UnB & 0.200 & UFRGS & 0.118 \\
UFRJ & 0.216 & UFRJ & 0.124 \\
Unicamp-Cien Soc & 0.240 & UFSCar & 0.131 \\
Ucam & 0.243 & USP & 0.179 \\
UFRN & 0.250 & Ufba & 0.200 \\
UFSCar & 0.250 & Unicamp-Cien Soc & 0.202 \\
UFPE & 0.273 & Fufse & 0.209 \\
Unicamp-Soc & 0.277 & UFPR & 0.214 \\
Ufma & 0.318 & UFPB-JP & 0.215 \\
UFMG-Soc & 0.333 & UFMG & 0.230 \\
UFC & 0.333 & UFRRJ-Cien Soc & 0.237 \\
UFJF & 0.333 & Unesp-Mar & 0.250 \\
Ufpa-Cien Soc & 0.333 & UEL & 0.250 \\
UFRGS & 0.333 & Unesp-Arar & 0.250 \\
& & UFRN & 0.250 \\
\hline
\end{tabular}

Fonte: Elaborado pelo autor a partir de dados da Plataforma Lattes.

Vale ressaltar que os brokers não necessariamente possuem alto grau de centralidade, mas desempenham papel fundamental na ligação entre os subgrupos da rede. Mais à frente, será

\footnotetext{
${ }^{5}$ Utilizamos a medida pelo método Whole Network em Ucinet. As medidas são computadas para todos os nós da rede, tratando cada nó por sua vez, como ego.
} 
apresentada a correlação entre a posição de broker e a produtividade dos PPGS.

\section{COESÃO SOCIAL E PRODUTIVIDADE CIENTÍFICA}

Com a finalidade de medir a produtividade dos PPGS, criamos escores per capita, considerando as publicações científicas informadas à Capes, tanto as produzidas em coautoria quanto as individuais. Mesmo cientes das limitações para determinar a qualidade das publicações, estabelecemos uma equação que atribuiu pesos de acordo com a qualificação (Qualis) dada pela Capes aos periódicos nos quais foram publicados os artigos, sendo que este tipo de publicação recebeu peso maior do que livros e capítulos:

Produtividade per capita $=(\mathrm{A} 1+\mathrm{A} 2+\mathrm{B} 1+\mathrm{B} 2+\mathrm{B} 3+\mathrm{B} 4+\mathrm{B} 5+$ livros + capítulos + coletâneas + verbetes) / média de docentes permanentes anual.

Produtividade ponderada per capita $=\{[(\mathrm{A} 1 \times 1,00+\mathrm{A} 2 \times 0,85+\mathrm{B} 1 \times 0,70+\mathrm{B} 2 \times 0,60+$ $\mathrm{B} 3 \times 0,40+\mathrm{B} 4 \times 0,30+\mathrm{B} 5 \times 0,1) \times 0,80]+[($ livros textos integrais $\times 0,90+$ capítulos $\times 0,15$ + coletâneas $\times 0,10+$ verbetes e outros $\times 0,05) \times 0,20]\} /$ média de docentes permanentes anual.

A Tabela 7 mostra a produtividade da área e a evolução de um triênio ao outro.

Tabela 7 - Escores de produtividade

\begin{tabular}{|c|c|c|c|}
\hline Descrição & $1^{\circ}$ Triênio & $2^{\circ}$ Triênio & Evolução \\
\hline Produtividade per capita da área & 10,311 & 11,292 & $9,51 \%$ \\
\hline Produtividade ponderada per capita da área & 1,670 & 1,892 & $13,29 \%$ \\
\hline
\end{tabular}

Fonte: Elaborado pelo autor a partir das avaliações trienais da Capes (COORDENAÇÃO DE APERFEIÇOAMENTO DE PESSOAL DE NÍVEL SUPERIOR, 2010, 2013).

Houve evolução da produtividade tanto em termos de quantidade quanto de qualidade. Pelo Gráfico 1, observa-se a evolução da quantidade de artigos publicados nos dois triênios. 


\section{Gráfico 1- Artigos por extrato Qualis}

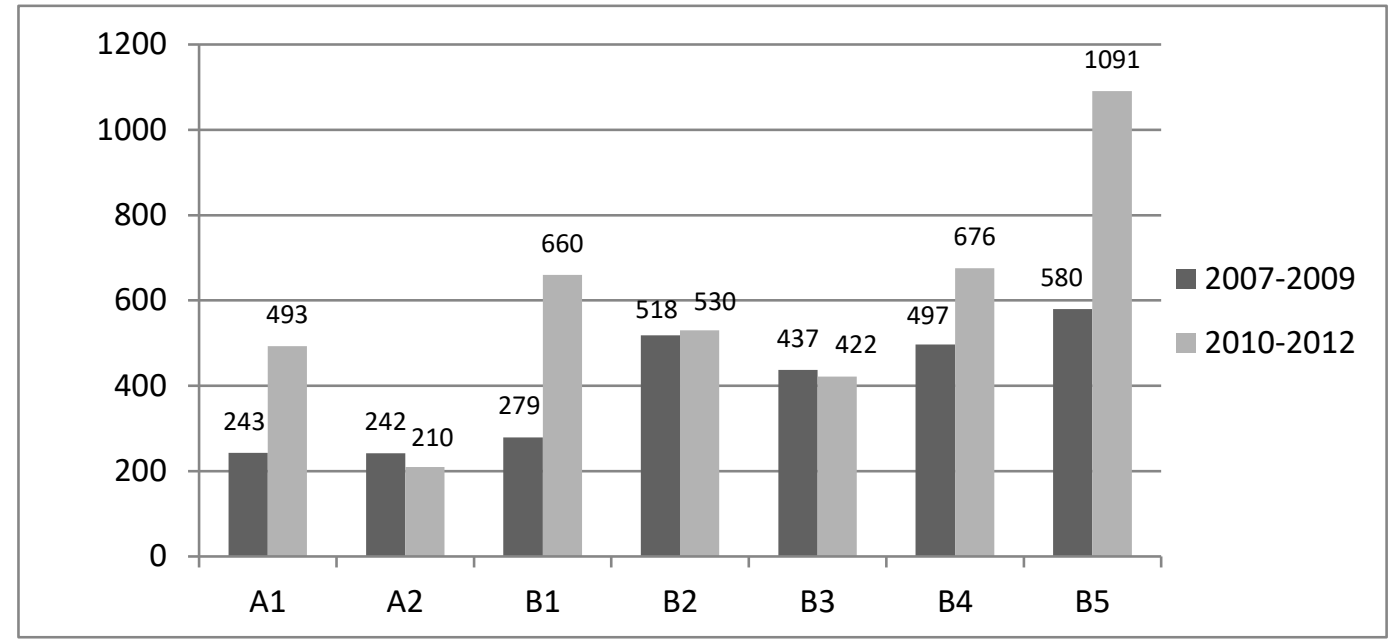

Fonte: Elaborado a partir da Avaliação Trienal Capes (COORDENAÇÃO DE APERFEIÇOAMENTO DE PESSOAL DE NÍVEL SUPERIOR, 2010, 2013).

A produção total de artigos qualificados cresceu $46 \%$ de um triênio para outro. Houve crescimento da quantidade de artigos nos estratos de Qualis A1, B1, B2, B4 e B5, apenas A2 e B3 apresentaram uma queda na produção. O estrato que apresentou maior crescimento foi o de Qualis B1, na ordem de 136,56\%, seguido de A1, que cresceu 102,88\%; B5, que cresceu $88,10 \%$; B4 que cresceu 36,02\%; e, por último, B2, com crescimento de 2,32\%. O aumento da coesão social nas redes de coautoria foi acompanhado pelo aumento da quantidade e da qualidade da produção científica.

\section{AMPLIANDO A ANÁLISE PARA O PERÍODO DE 2007 A 2012}

Dadas as baixas densidades das redes por triênios, mostradas anteriormente, e com a finalidade de aprofundar as análises sobre a estrutura relacional dos atores e a produtividade científica, montou-se a rede de coautoria englobando os dois triênios. Isso permitiu observar uma rede um pouco mais densa e com componentes maiores. A rede total englobou 1.208 pesquisadores, conforme a Figura 5.

A rede de coautoria se mostrou fragmentada em 126 componentes, representando 567 atores, ou seja, 46,94\% do total de docentes da área. O maior grupo foi composto por 152 vértices, que representou $12,58 \%$ do total de docentes e $26,81 \%$ dos que possuíam algum laço de coautoria. 


\section{Figura 5 - Docentes com coautoria de 2007 a 2012}

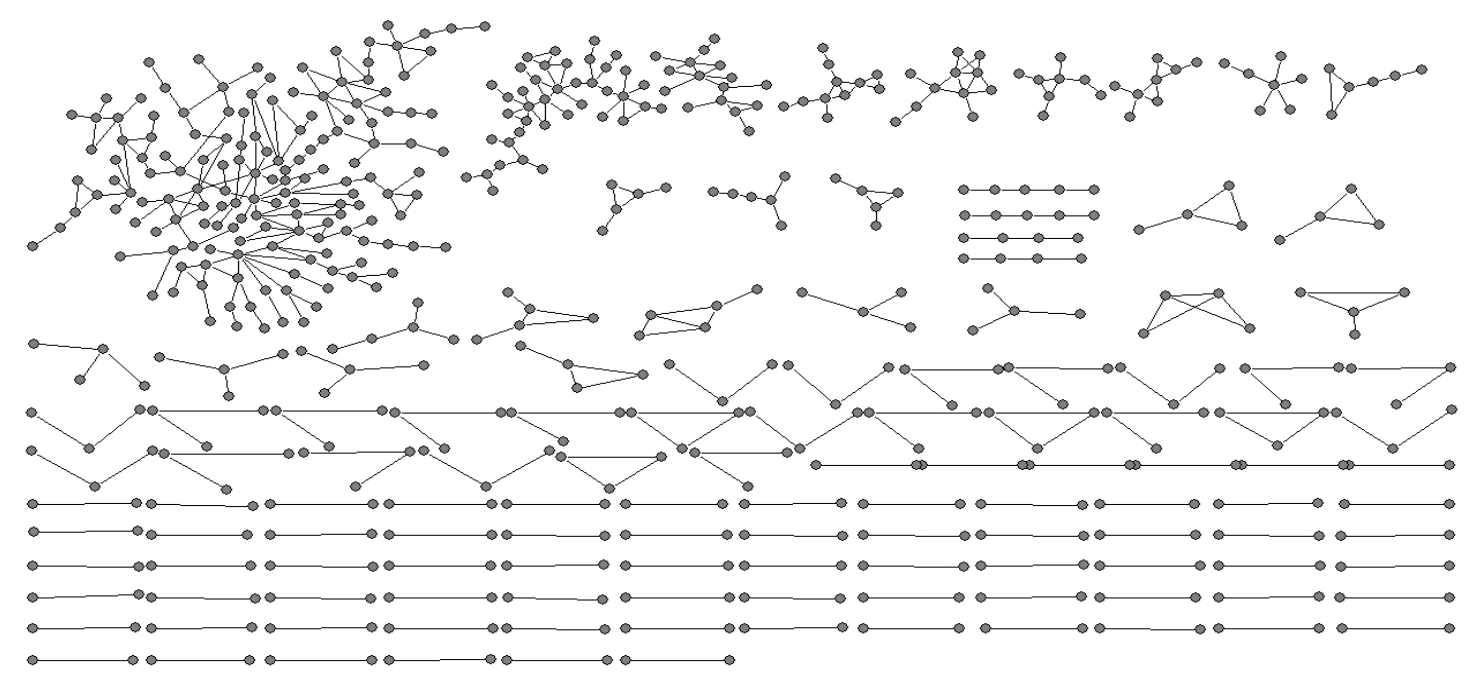

Fonte: Elaborado pelo autor a partir de dados da Plataforma Lattes.

\section{ANÁLISE DO MAIOR COMPONENTE DA REDE 2007-2012}

O maior componente da rede representa a mais extensa teia de relações entre pesquisadores do campo científico. No entanto, o tamanho do componente em relação ao universo de pesquisadores da área (12,58\%) mostra como a coesão por coautoria é pequena na Sociologia. Os valores apresentados na Tabela 8 evidenciam isso. É uma rede de baixa densidade (3,1\%), pois possui um grau de separação relativamente alto (9,2 laços), ou seja, em média, as pessoas estão separadas por nove passos. A rede tem um diâmetro também elevado (25 laços) e uma média de pouco mais de dois laços de coautoria por autor.

\section{Tabela 8 - Estatísticas descritivas do maior componente}

\begin{tabular}{cc}
\hline Descrição & Dados \\
\hline Quantidade de atores conectados $(n)$ & 152 \\
Laços de coautoria científica (arestas) & 356 \\
Média de laços por ator $(k)$ & 2,342 \\
Grau de centralidade total da rede (degree) & 0,038 \\
Densidade da rede & 0,031 \\
Diâmetro da rede & 25 \\
Distância média geodésica (observada) & 9,2 \\
Coeficiente de agrupamento geral (observado) & 0,244 \\
\hline
\end{tabular}

Fonte: Elaborado pelo autor a partir de dados da Plataforma Lattes.

Então questionamos se a colaboração científica seria uma boa estratégia para aumentar a produtividade. A Tabela 9 traz uma comparação entre a produtividade do maior componente da rede e a área total da Sociologia.

Tabela 9 - Comparação de produtividades científicas - 2007 a 2012 
Maia / Colaboração científica e produtividade na pós-graduação em Sociologia e Ciências Sociais no Brasil

\begin{tabular}{c|c|c|c}
\hline Descrição & $\begin{array}{c}\text { Maior } \\
\text { Componente }\end{array}$ & Área total & $\begin{array}{c}\text { Maior componente / } \\
\text { Área total }\end{array}$ \\
\hline Produtividade per capita & 16,678 & 18,624 & $-10,45 \%$ \\
Produtividade ponderada per capita & 3,549 & 3,308 & $7,29 \%$ \\
\hline
\end{tabular}

Fonte: Elaborado pelo autor a partir dos dados das avaliações trienais da Capes (COORDENAÇÃO DE APERFEIÇOAMENTO DE PESSOAL DE NÍVEL SUPERIOR, 2010, 2013) e currículos da Plataforma Lattes.

O maior agrupamento de atores da rede mostrou uma produção de maior qualidade do que a área como um todo. Mesmo apresentando uma quantidade per capita $10,45 \%$ menor, sua produtividade ponderada pelos Qualis foi 7,29\% maior que a da área como um todo. Portanto, há indícios de que a maior integração em termos de relações de coautoria beneficia a produtividade, pelo menos quanto à qualidade da produção.

\section{COMUNIDADES DE PRODUÇÃO DO MAIOR COMPONENTE}

As redes podem apresentar subgrupos de atores que demonstram maior interação. Integrantes de determinados grupos podem ter interesses de pesquisa em comum, estar próximos geograficamente, possuir a mesma filiação institucional, participar dos mesmos grupos de pesquisa, orientar e serem orientados, trocar conhecimentos entre si etc. Estes subgrupos formam as comunidades de produção e, usando os termos de Price (1961) e Crane (1972), poderíamos chamá-los de colégios invisíveis. A densidade das relações dentro destes subgrupos é maior que a densidade destes com os demais. A Figura 6 mostra o maior componente da rede 2007-2012 pelas 13 comunidades detectadas ${ }^{6}$.

A comunidade 11 apresenta uma estrutura peculiar, sem fechamento estrutural (não há uma tríade sequer nesta comunidade), sendo assim, é um subgrupo com baixa coesão interna. No entanto, esta comunidade desempenha uma função primordial na intermediação da rede: sua ausência quebraria a estrutura em quatro partes. As outras comunidades, se ausentes, quebrariam o componente em apenas duas partes, ou nem o partiriam - caso das comunidades localizadas nas extremidades das ramificações: 8, 1, 6, 2 e 4. As comunidades 12, 10, 9, 5 e 3 são as que possuem maior fechamento estrutural interno, ou seja, duas ou mais tríades. A comunidade 7 também não possui fechamento estrutural, mas é responsável por ligar duas regiões do componente.

Figura 6 - Maior componente da rede 2007-2012 por comunidades

\footnotetext{
${ }^{6} \mathrm{Cf}$. nota 2 . O componente da rede 2007-2012 apresentou modularidade de 0,851.
} 
Maia / Colaboração científica e produtividade na pós-graduação em Sociologia e Ciências Sociais no Brasil

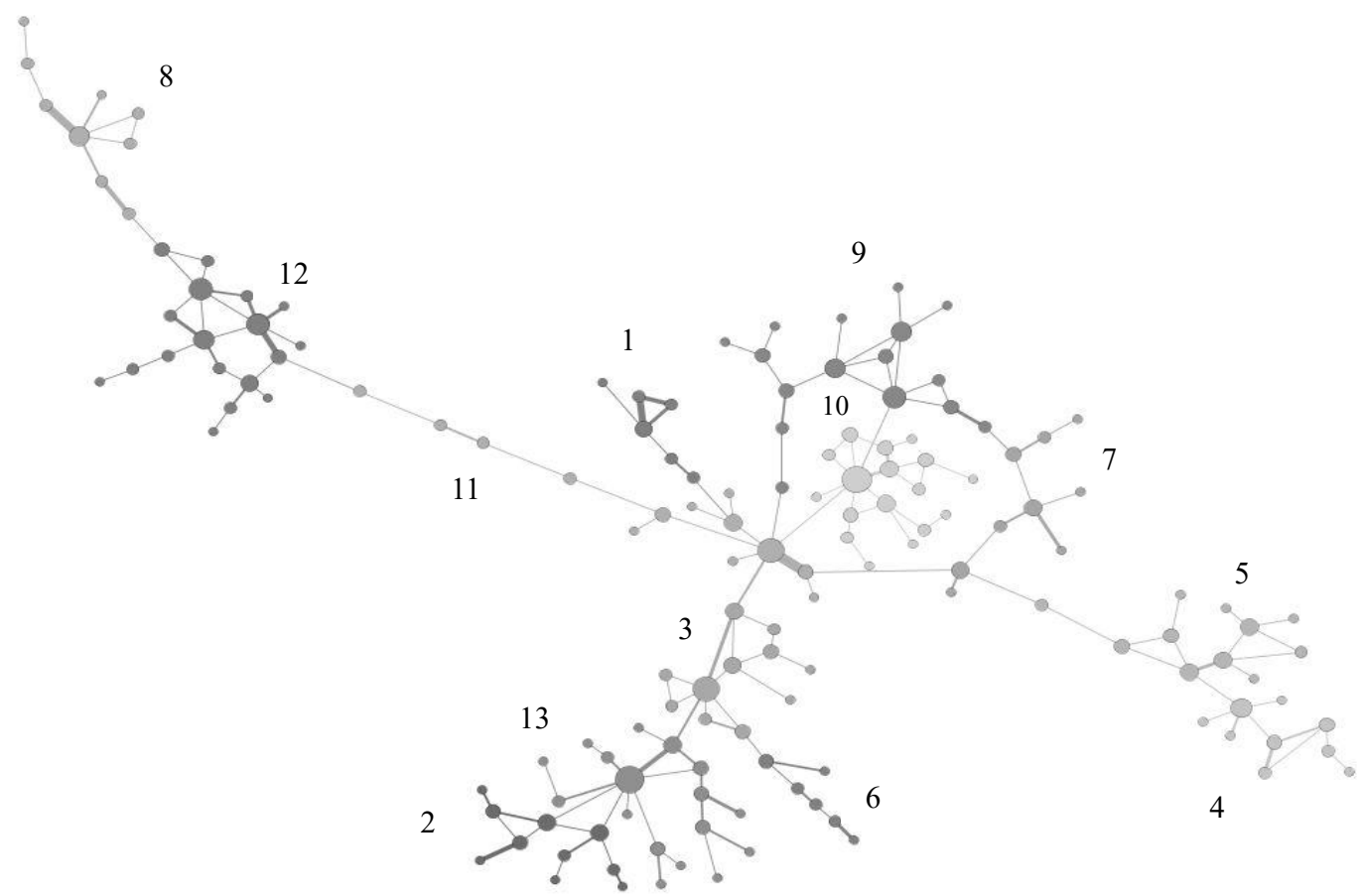

Fonte: Elaborado pelo autor a partir de dados da Plataforma Lattes.

Nota: A tonalidade dos vértices e arestas representa as comunidades; o tamanho dos vértices, a centralidade de grau.

O Quadro 2 mostra as áreas temáticas ${ }^{7}$ sobre as quais os pesquisadores das comunidades se debruçaram em suas pesquisas durante aquele período.

\section{Quadro 2 - Temáticas de pesquisa das comunidades no período 2007-2012}

\begin{tabular}{|c|l|}
\hline Comunidades & \multicolumn{1}{c|}{ Temáticas } \\
\hline 1 & Sociologia rural, meio ambiente e conflitos. \\
\hline 2 & $\begin{array}{l}\text { Sociologia ambiental, sociologia rural, sociologia das migrações, sociologia da ciência e } \\
\text { tecnologia. }\end{array}$ \\
\hline 3 & Sociologia econômica, do trabalho e sindicalismo. \\
\hline 4 & Antropologia urbana, sociologia da violência, sexualidade, gênero e família. \\
\hline 5 & $\begin{array}{l}\text { Sociologia da religião, estudos sobre gênero, sexualidade e violência, teoria Queer, } \\
\text { criminologia e direitos humanos. }\end{array}$ \\
\hline 6 & Sociologia do trabalho, desigualdades de gênero, geracionais e étnico-raciais. \\
\hline 7 & Sociologia do trabalho. \\
\hline 8 & $\begin{array}{l}\text { Participação social, gestão pública participativa, cidadania, agricultura familiar e } \\
\text { desenvolvimento territorial. }\end{array}$ \\
\hline 9 & $\begin{array}{l}\text { É uma comunidade que não forma um subgrupo com homogeneidade temática, as ligações } \\
\text { entre os atores se deram principalmente por meio de participação em livros e capítulos de } \\
\text { livros tipo coletâneas, com temáticas diversas, como: teoria sociológica; trabalho e gênero; } \\
\text { educação; sexualidade, feminismo, e violência. }\end{array}$ \\
\hline
\end{tabular}

\footnotetext{
${ }^{7}$ Detectadas por meio da análise do conteúdo dos currículos Lattes, verificando-se as áreas de atuação declaradas e as publicações em coautoria durante o período 2007-2012 e, posteriormente, sintetizando-se as temáticas comuns.
} 
Maia / Colaboração científica e produtividade na pós-graduação em Sociologia e Ciências Sociais no Brasil

\begin{tabular}{|c|l|}
\hline 10 & Sociologia do trabalho, economia solidária, sociologia da violência e conflitos sociais. \\
\hline 11 & $\begin{array}{l}\text { Antropologia rural e questões socioambientais, trabalho e sindicalismo, cultura e religiões } \\
\text { afro-brasileiras. }\end{array}$ \\
\hline 12 & $\begin{array}{l}\text { Sociologia rural, agricultura familiar e desenvolvimento sustentável, vulnerabilidade } \\
\text { socioambiental. }\end{array}$ \\
\hline 13 & $\begin{array}{l}\text { Sociologia da ciência e desenvolvimento tecnológico, sociologia do conhecimento, } \\
\text { sociologia do trabalho. }\end{array}$ \\
\hline
\end{tabular}

Fonte: Elaborado pelo autor a partir dos currículos Lattes.

As comunidades apresentam pontos de sobreposição de temáticas semelhantes. Estas semelhanças são dadas por meio de artigos, livros ou capítulos de livros publicados em coautoria, sobre temas que aproximam os subgrupos. Pela verificação das publicações conjuntas dos atores que ligam as comunidades, ou seja, dos principais brokers, encontramos os seguintes assuntos:

- 8 e 12: Agricultura familiar.

- 12 e 11: Sociologia rural e questões socioambientais.

- 11 e 3: Trabalho e sindicalismo.

- 3 e 6: Sociologia do trabalho.

- 3 e 13: Sociologia do trabalho.

- 13 e 2: Sociologia da ciência e tecnologia.

- 11 e 1: Sociologia rural e questões socioambientais.

- 11 e 9: A ligação foi dada por dois atores com capítulos publicados em um livro do tipo coletânea (MORAES, 2011), sendo um capítulo sobre metodologia do ensino de ciências sociais e outro sobre trabalho na sociedade contemporânea.

- 9 e 10: Sociologia do trabalho.

- 10 e 11: Sociologia do trabalho.

- 9 e 7: Sociologia do trabalho.

- 7 e 5: A ligação foi dada pela participação de dois atores na organização de um livro do tipo coletânea que trata sobre processos de "territorialização" e identidades sociais na região amazônica (PINTO; MORAIS; LIMA, 2012).

- 5 e 4: Gênero, sexualidade e violência.

- 7 e 11: Sociologia do trabalho.

Segundo a hipótese de capital social defendida por Coleman (1988), uma estrutura relacional mais enclausurada - consequentemente com maior densidade - favoreceria o 
surgimento de normas e de controle social. Não é o caso da estrutura relacional dos pesquisadores pertencentes ao principal componente da rede, que se mostrou de baixa densidade. É uma rede com baixo fechamento estrutural. No entanto, a análise das temáticas de pesquisa de cada comunidade detectada deixou clara a importância dos laços fracos e das pontes entre os subgrupos, que são responsáveis por canalizar o fluxo de informações não redundantes de um lado a outro. As informações podem fluir de uma comunidade a outra por meio das relações entre atores encontrados nas fronteiras, ou seja, à beira de buracos estruturais (BURT, 1992).

Finalmente, as comunidades de produção realizam pesquisas em temáticas diversas. No entanto, a temática mais recorrente, ou seja, que interliga mais subgrupos, foi sociologia do trabalho, seguida de sociologia rural, agricultura familiar e questões socioambientais, sociologia da ciência e tecnologia, e gênero, sexualidade e violência.

\section{A REDE 2007-2012 REDUZIDA}

Durante esse período existiram 53 PPGS, mas foram desconsiderados dois programas: Unioeste, que apresentou apenas coautorias internas, e UFMG-Sociologia Política, que foi extinto em 2010. Sendo assim, a rede foi constituída por 51 nós e 155 arestas. A Figura 7 mostra o grafo da rede pelas seis comunidades ${ }^{8}$ encontradas.

Figura 7 - Rede de PPGS 2007-2012 por comunidades

\footnotetext{
${ }^{8} \mathrm{Cf}$. nota 2. Modularidade rede reduzida 2007-2012 $=0,536$.
} 


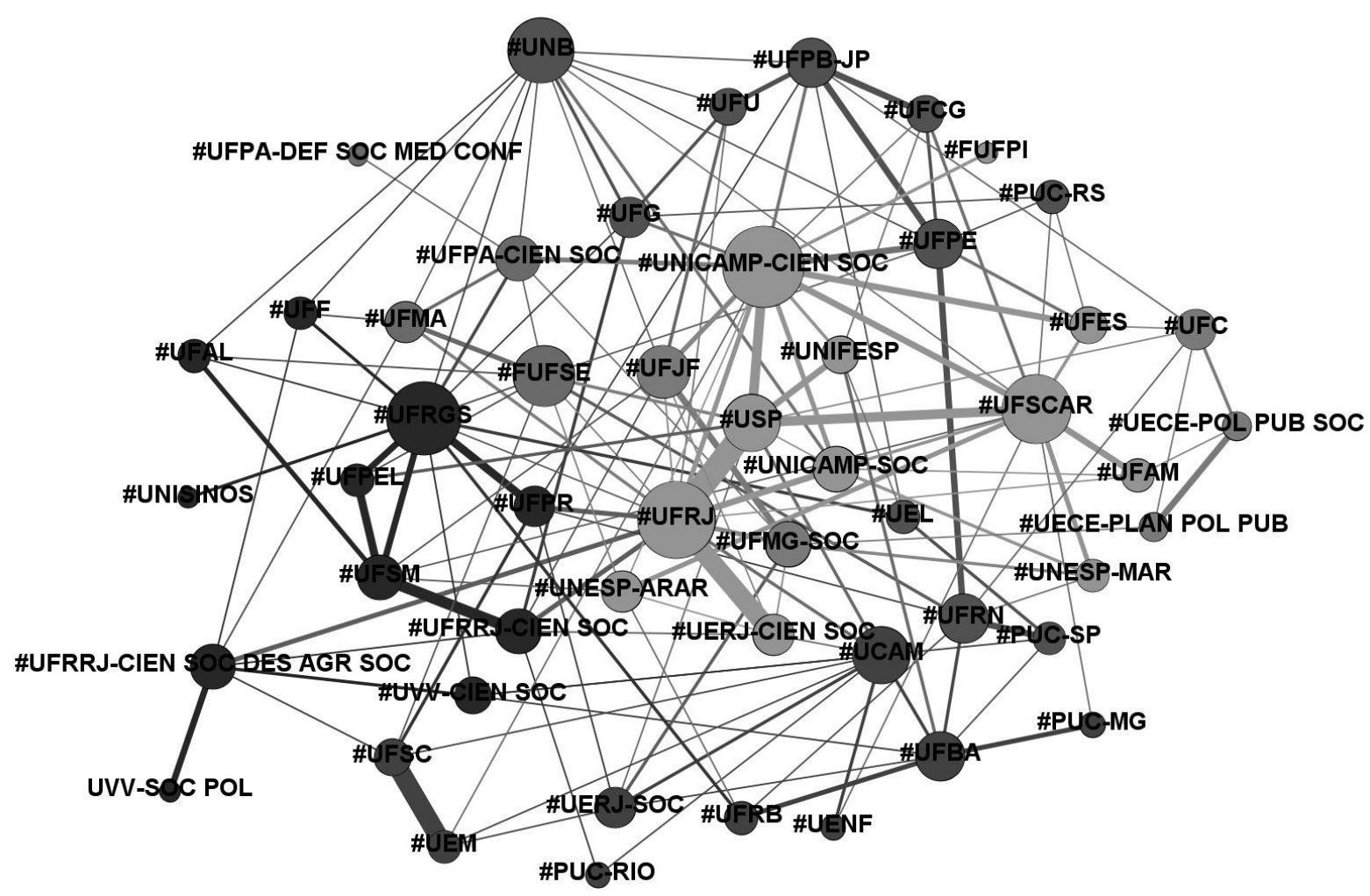

Fonte: Elaborado pelo autor a partir de dados da Plataforma Lattes.

Nota: As tonalidades das arestas e dos vértices indicam as comunidades; a espessura das arestas indica a quantidade de coautorias, e o tamanho dos vértices, a centralidade de grau.

A rede elaborada ao nível dos PPGS permite uma visualização do campo como um todo, pois agora tomamos as relações de coautoria não pelos pesquisadores, mas por suas instituições. Desta forma, não temos uma rede fragmentada em diversos componentes, mas uma rede única. A Tabela 10 traz as métricas básicas sobre a rede unificada, vistas pelo nível das relações interinstitucionais e considerando a rede binária. Nota-se que, de forma geral, é uma rede de baixa densidade e de baixa "clusterização".

Tabela 10 - Estatísticas descritivas da rede reduzida 2007-2012

\begin{tabular}{ll}
\hline \multicolumn{1}{c}{ Descrição } & \multicolumn{1}{c}{ Dados } \\
\hline Quantidade de atores conectados (vértices) & 51 \\
Laços de coautoria científica (arestas) & 155 \\
Média de laços por PPGS & 3,039 \\
Grau de centralidade total da rede (degree) & 0,186 \\
Densidade da rede & 0,122 \\
Diâmetro da rede & 5 \\
Distância média geodésica & 2,4 \\
Coeficiente de agrupamento geral & 0,059 \\
\hline
\end{tabular}

Fonte: Elaborado pelo autor a partir de dados da Plataforma Lattes.

De 2.550 laços possíveis, há apenas 155 de coautoria ligando os PPGS, o que resultou 
na baixa densidade da rede. Nos extremos, há os PPGS que se conectaram somente a um programa (Fufpi, Unisinos, UVV-Soc Pol, Ufpa-Def Soc Med Conf) e programas que se conectaram a outros 15 (Unicamp-Cien Soc, UFRJ), mas, em média, os PPGS se conectaram a três outros programas. O grau de centralidade total da rede $(0,186)$ mostra que, mesmo com alguns programas mais centrais, os laços de coautoria não estão totalmente nas mãos de somente um ou poucos programas. O diâmetro da rede foi de cinco laços e, em média, os PPGS estão separados por 2,4 passos. O diâmetro dá uma noção da extensão da rede, e a distância média geodésica (graus de separação) indica a separação média entre dois nós quaisquer. Uma rede mais densa resultaria em diâmetro e graus de separação menores.

O grau de "clusterização" da rede não se mostrou elevado $(0,059)$, isso quer dizer que os PPGS não se encontram fortemente divididos em subgrupos de alta coesão interna. Ao observar a Figura 7, percebe-se que as comunidades detectadas, mesmo possuindo maior densidade de relações internas, não são tão separadas das demais. Sendo assim, a rede não apresenta uma topologia com buracos estruturais evidentes. Isso pode indicar uma baixa diversidade de especialização temática na área.

\section{POSIÇÕES ESTRUTURAIS E PRODUTIVIDADE}

Por um lado, o resultado dos programas em termos de produtividade pode advir do capital humano encerrado dentro deles próprios, mas, por outro, podemos considerar que a posição dos programas em termos de colaboração científica externa também pode influenciar a produtividade. Temos assim duas perspectivas: uma que olha para dentro de cada nó, ou seja, considera apenas o capital intelectual dos docentes e pesquisadores componentes da cada PPGS como fator gerador da produtividade, e outra que olha para a posição ocupada pelos programas na rede de colaboração científica, para os laços que unem os atores.

A capacidade individual para a tomada de decisões no campo de interações suscita o capital humano, enquanto os aspectos coletivos e estruturais que restringem ou facilitam as ações individuais resultam no capital social (BOURDIEU, 1980; COLEMAN, 1988). Nesta pesquisa, concentramo-nos em aspectos estruturais que poderiam interferir na produtividade, ou seja, optamos pela segunda perspectiva - a da análise dos PPGS na rede de coautoria. Então verificamos como a posição dos PPGS na rede impacta na produtividade sob três aspectos: posição de centralidade; posição de intermediação entre subgrupos (brokers); e grau de externalidade das relações.

\subsection{Posição de centralidade}

Sobre o primeiro aspecto, buscamos responder à seguinte questão: seriam os PPGS centrais mais produtivos que os demais? Para isso, verificamos se as medidas de centralidade estão associadas linearmente à produtividade dos PPGS. As análises de regressão linear simples entre as principais medidas de centralidade e os escores de produtividade dos PPGS segundo 
Maia / Colaboração científica e produtividade na pós-graduação em Sociologia e Ciências Sociais no Brasil

suas produções qualificadas $^{9}$ são apresentados na Tabela 11.

Tabela 11 - Regressão linear e correlações entre centralidade e produtividade científica

\begin{tabular}{|c|c|c|c|}
\hline \multirow[b]{2}{*}{ Centralidade } & \multicolumn{3}{|c|}{ Produtividade } \\
\hline & $\mathbf{R}^{2}$ & $\begin{array}{c}\text { Coeficiente linear } \\
(\alpha)\end{array}$ & $\begin{array}{l}\text { Coeficiente } \\
\text { angular }(\beta)\end{array}$ \\
\hline De grau (degree) & 0,3093 & 0,1357 & 0,0379 \\
\hline De intermediação (betweenness) & 0,2748 & 0,2649 & 0,0360 \\
\hline De proximidade (closeness) & 0,2763 & $-0,6112$ & 0,0228 \\
\hline
\end{tabular}

Fonte: Dados da rede processados em Stata.

Os coeficientes de determinação $\left(\mathrm{R}^{2}\right)$ encontrados mostram que a centralidade de grau explica 30,93\% da variabilidade da produtividade, enquanto a intermediação e a proximidade explicam 27,48\% e 27,63\%, respectivamente. Os coeficientes lineares $(\alpha)$ mostram que, se a centralidade de grau fosse igual a zero, isto é, o PPGS não tivesse nenhum laço de coautoria, sua produtividade seria igual a 0,1357 . Se a centralidade de intermediação fosse igual a zero (se o PPGS não estivesse entre nenhum par de programas), sua produtividade seria igual a 0,2649. Se a centralidade de proximidade fosse igual a zero (isso só ocorreria se o PPGS estivesse desconectado da rede, ou seja, não tivesse nenhum laço de coautoria externa), sua produtividade seria de -0,6112. Esta representação é uma questão matemática, pois não existiria produtividade negativa, mas no mínimo zero.

Pelos coeficientes angulares $(\beta)$, a cada unidade aumentada na centralidade de grau, a produtividade do programa deveria aumentar em 0,0379. Para as centralidades de intermediação e de proximidade, aumentaria 0,0360 e 0,0228 respectivamente. Portanto, podemos afirmar que a produtividade é mais sensível à variação da centralidade de grau.

Constatamos que os PPGS com maior diversidade de laços de coautoria interinstitucionais se mostraram mais produtivos. No entanto, sabe-se que na área da Sociologia e Ciências Sociais muitas publicações qualificadas são produzidas por um só autor. Logo, a centralidade nas redes de coautoria, mesmo tendo boa correlação, não pode de forma isolada explicar a produtividade.

Desta forma, evidencia-se que as medidas de centralidade na rede apresentam correlação moderada e positiva com a produtividade dos programas.

\subsection{Posição de intermediação entre subgrupos (brokers)}

A teoria de capital social de Ronald Burt (1992) postula que os atores atuantes como brokers, ou seja, aqueles posicionados à beira dos buracos estruturais das redes sociais, se beneficiam pelo fluxo não redundante de informações e tecem conexões com subgrupos

\footnotetext{
${ }^{9}$ Escores da produção de artigos, livros e capítulos ponderados pelos Qualis conforme equação de produtividade ponderada per capita.
} 
diversos dentro da estrutura da rede, podendo, assim, tirar vantagem em termos de produtividade. Então perguntamos se os PPGS com maior autonomia estrutural seriam mais produtivos que os demais. Se isso ocorrer, os PPGS à beira de buracos estruturais deveriam ser mais produtivos que os PPGS constrangidos pela rede.

$\mathrm{O}$ algoritmo de constraint indica quanto um ator é constrangido pela estrutura da rede, quanto menos "constrangido", mais próximo de um buraco estrutural estará o ator. Procedemos então a uma correlação entre as variáveis constraint e produtividade. O modelo que se mostrou mais adequado para verificar esta correlação foi o da regressão pela lei de potência. O Gráfico 2 exibe essa correlação.

\section{Gráfico 2 - Constraint versus produtividade}

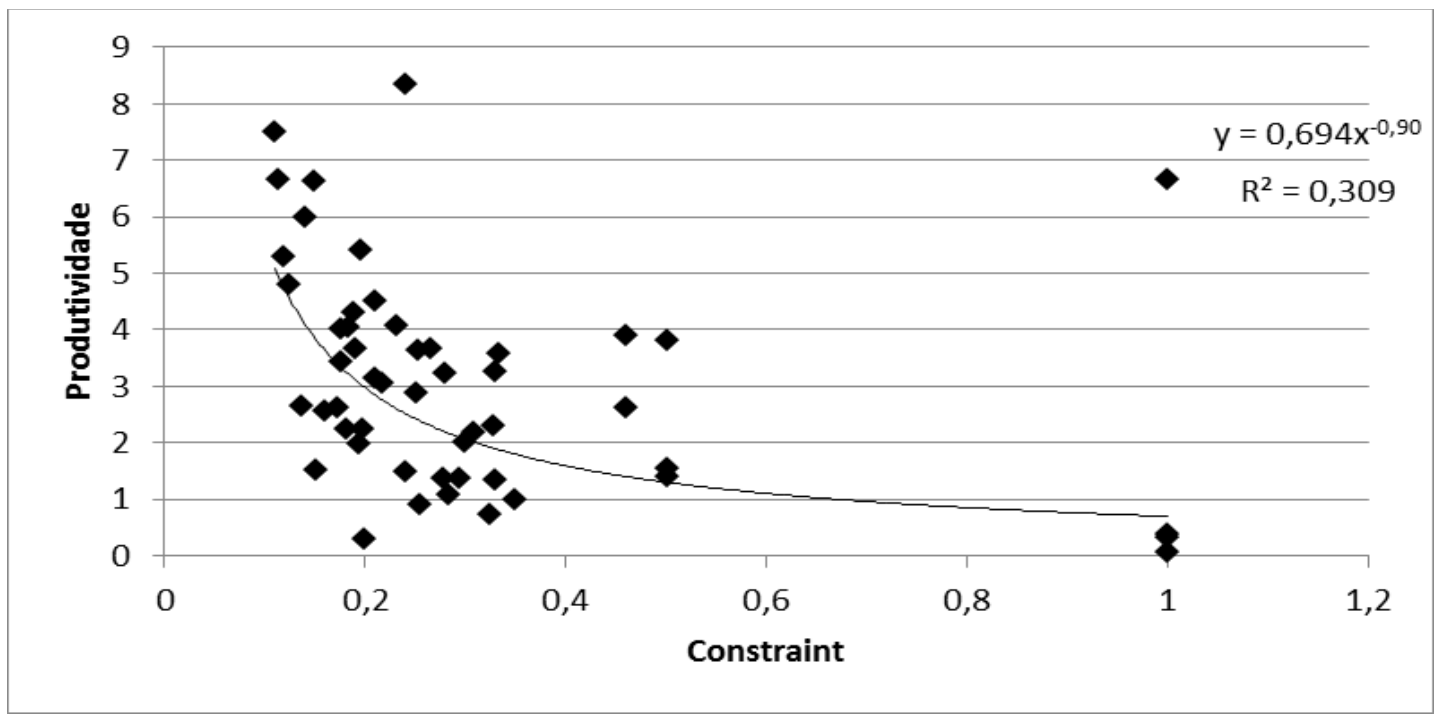

Fonte: Elaborado pelo autor.

O modelo resultou em um coeficiente de determinação moderado $\left(\mathrm{R}^{2}=0,309\right)$. A análise de correlação entre constraint e produtividade permitiu corroborar este pressuposto somente em parte, pois a correlação entre constraint e produtividade se mostrou moderada $(R=0,5566)$.

A rede de coautoria vista pelo nível das relações entre os PPGS é muito pouco "clusterizada", o coeficiente de agrupamento foi de 0,059 , bastante baixo. Desta forma, como não existem subgrupos bem definidos ${ }^{10} \mathrm{e}$ "buracos estruturais" tão evidentes, as posições de brokers parecem impactar tanto a produtividade quanto as posições de centralidade, visto que os coeficientes de correlação resultaram moderados.

\subsection{Grau de externalidade das relações}

Finalmente, sob o terceiro aspecto, podemos perguntar se os PPGS com mais coautorias

\footnotetext{
${ }^{10} \mathrm{O}$ algoritmo de modularidade detectou as comunidades de PPGS mais coesas entre si. No entanto, pelo baixo coeficiente de "clusterização", percebe-se que estes subgrupos não se encontram notoriamente separados por buracos estruturais.
} 
externas seriam mais produtivos que os PPGS com mais coautorias internas. A análise de regressão linear entre externalidade das relações de coautoria (E-I Index) e produtividade não resultou em nenhuma correlação satisfatória. Os índices de correlação e de determinação foram extremamente baixos $\left(\mathrm{R}=0,0683\right.$ e $\left.\mathrm{R}^{2}=0,0047\right)$.

Portanto, podemos afirmar que os PPGS que tecem maior quantidade de coautorias externas não serão necessariamente mais produtivos.

Por outro lado, a correlação entre centralidade de grau e produtividade foi positiva e relativamente moderada, mostrando que os programas com maior diversidade de laços interinstitucionais são mais produtivos. Ou seja, ter maior quantidade de coautorias externas do que internas parece impactar menos na produtividade do que possuir maior diversidade de relações externas. Maior quantidade de produção em coautorias internas pode indicar alto grau de coesão entre o corpo docente de um programa, por outro lado, a maior diversidade de relações externas pode indicar que o programa dispõe de pesquisadores mais qualificados e que seriam mais "procurados" para formar parcerias de pesquisa.

\section{CONSIDERAÇÕES FINAIS}

A área da Sociologia e das Ciências Sociais ainda é um campo científico muito fragmentado. A colaboração científica, que pode ser traduzida estritamente por meio da coautoria, não é comum entre os pesquisadores da área. A maior parte dos integrantes não teceu nenhum laço e outra parte considerável apresentou poucos laços de coautoria. Por este motivo, optou-se por trabalhar com as redes reduzidas aos PPGS de afiliação dos atores em lugar das redes pessoais, que se apresentaram fragmentadas em diversos componentes menores, como díades e tríades isoladas, não permitindo uma análise completa por meio das técnicas da ARS.

Portanto, o caso particular desta área refuta a generalização comum na literatura, de que as comunidades científicas formam redes altamente interconectadas e "clusterizadas". Não obstante, ressaltamos as limitações deste estudo: 1) o corte temporal curto - dois triênios; 2) o fato de que coautorias são menos frequentes nas Ciências Sociais; 3) o corte dado na coleta de dados - somente artigos, livros e capítulos. Destarte, tais limitações são inerentes à metodologia utilizada e às idiossincrasias do objeto de estudo.

A comparação entre os dois triênios permitiu a verificação da evolução da área em termos de aumento de coesão social e ganho de produtividade. Já a análise da rede de coautoria do período completo (2007 a 2012) permitiu testar algumas hipóteses acerca das posições estruturais dos PPGS na rede de coautoria e produtividade. De forma sintética, os achados obtidos na comparação entre as redes de coautoria dos dois triênios foram:

a) aumento do percentual de pesquisadores com publicações em coautoria (de 28,99\% para $34,43 \%)$

b) os programas passaram a ter mais relações interinstitucionais, vistas pela elevação do E-I Index;

c) o maior subgrupo coeso da rede de coautoria (componente principal), em termos qualitativos, é mais produtivo que a área como um todo.

O aumento da coesão social impactou de forma positiva na produtividade geral da área. 
Os programas com maior diversidade de laços interinstitucionais de coautoria se mostraram mais produtivos. Isto sugere que uma maior imbricação dos PPGS na área, por meio do aumento da diversidade de relações interinstitucionais de pesquisa, pode trazer ganhos de produtividade.

A área experimentou grande avanço ao longo desses dois triênios. Mesmo com a entrada de 11 novos programas, que podem não possuir linhas de pesquisa plenamente consolidadas e pesquisadores de alta senioridade, a produtividade geral da área parece se beneficiar com o aumento da coesão social de seus integrantes, vista pela maior intensidade e diversidade das relações entre os atores. Finalmente, a área poderá obter ganhos de produtividade científica à medida que as relações entre seus atores se tornarem mais frequentes e mais especializadas.

\section{Referências}

BLONDEL, V. D. et al. Fast unfolding of communities in large networks. Journal of Statistical Mechanics: Theory and Experiment, New York, v. 2, p. 1-12, 2008.

BOURDIEU, P. Le capital social. Actes de la Recherche en Sciences Sociales, Paris, v. 31, n. 1, p. $2-3,1980$.

BURT, R. S. Structural holes: the social structure of competition. Cambridge (MA): Harvard University Press, 1992.

Structural holes versus network closure as social capital. In: LIN, N.; COOK, K.; BURT, R. S. (Ed.). Social capital: theory and research. New York: Aldine de Gruyter, 2001. p. 31-56.COLEMAN, J. S. Social Capital in the creation of human capital. The American Journal of Sociology, Chicago, v. 94, p. S95-S120, 1988.

COORDENAÇÃO DE APERFEIÇOAMENTO DE PESSOAL DE NÍVEL SUPERIOR. Relatório de Avaliação Trienal 2010. 2010. Disponível em: <http://bit.ly/2t9k6ff $>$. Acesso em: 2 set. 2015.

. Relatório de Avaliação Trienal 2013. 2013. Disponível em: $<$ http://bit.ly/2tsWbu8>. Acesso em: 2 set. 2015.

CRANE, D. Invisible colleges: diffusion of knowledge in scientific communities. Chicago: The University of Chicago Press, 1972.

FREEMAN L. C. A set of measures of centrality based on betweenness. Sociometry, Ann Arbor, v. 40, n. 1, p. 35-41, 1977.

Centrality in social networks: conceptual clarification. Social Networks, Amsterdam, v. 1, n. 3, p. 215-239, 1979.

GRANOVETTER, M. The strength of weak ties. American Journal of Sociology, Chicago, v. 78, n. 6, p. 1360-1380, 1973. 
. The strength of weak ties: a network theory revisited. Sociological Theory, Thousand Oaks, v. 1, p. 201-233, 1983.

.The impact of social structure on economic outcomes. Journal of Economic

Perspectives, Nashville, v. 19, n. 1, p. 33-50, 2005.

LAMBIOTTE, R.; DELVENNE, J. C.; BARAHONA, M. Laplacian Dynamics and Multiscale Modular Structure in Networks. Physics and Society, New York, v. 3, p. 1-29, 2009.

LEMIEUX, V.; OUIMET, M. Análise estrutural das redes sociais. 2. ed. Lisboa: Epistemologia e Sociedade, 2012.

MENA-CHALCO, J. P.; CESAR JUNIOR, R. M. ScriptLattes: an open-source knowledge extraction system from the lattes platform. Journal of the Brazilian Computer Society, Porto Alegre, v. 15, n. 4, p. 31-39, 2009.

MORAES, A. C. (Org.). Sociologia. Brasília, DF: Ministério da Educação, 2011. v. 15. (Coleção Explorando o Ensino).

PINTO, M. C. O. B. S.; MORAIS, M. J.; LIMA, J. C. (Org.). Processos de territorialização e identidades sociais. São Carlos: Rima, 2012. v. 2.

PRICE, D. J. S. Science since Babylon. New Haven: Yale University Press, 1961.

Recebido em 18/11/2016

Aprovado em 10/05/2017 